\title{
Book review - Boekresensie
}

\section{The genetics of cattle}

\author{
Edited by R Vries and A Ruvinsky
}

2000. CABI Publishing, Wallingford and N ew York, 720 pp., hard cover. Price f99.50 (U S\$185). ISBN 0851992587.

This book comprises 24 chapters written by different authors. The topics of the different chapters are arranged in a logical sequence, starting with the history of cattle and genetics and progressing from basic genetics to molecular genetics and thereafter to applied genetics. Most of the authors are world-renowned geneticists, making this book a rich source of information and references for anyone wanting to know about this topic. Chapter 1 is about the systematics and phylogeny of cattle and makes interesting reading about the different cattle types of the world. Chapter 2, on genetic aspects of domestication, gives the history of progression to the domestication of cattle throughout the world and how the domesticated animal shaveadapted to different parts of the world and their environment. Chapter 3 refers to the colour variants, but only European breeds are discussed, and no reference is made to the colour variation of breeds such as the N guni, and its genetics. Chapter 4 is primarily a tabulated overview of the genetics of morphological traits and inherited disorders of cattle. The author suggests that many new discoveries will be made in the near future.

Chapter 5 discuses blood groups and biochemical polymorphismsat great length, and is moreacademicthan most of the other chapters.

Chapters 6 and 7 discuss molecular genetics in such detail that, without a molecular genetics background, the reader loses thethread. Chapter 7 deals with the molecular genetics of molecules with immunological functions (major histocompatibility complex, immuno-globulins, T-cell receptors, cytokines and their receptors).

Chapter 8 covers the genetics of disease resistance and referenceismadeto parasitological research in South Africa.

Chapter 9 deals with bovine spongiform encephalopathy, and is very informative, as this disease has had such an important impact on the beef industry worldwide, although South Africa has not been exposed to the disease.

Chapters 10 and 11 deal with mapping the genome of cattle, and the lists are very long, consisting of 82 pages listing all the genes on the chromosome map. This is mainly of academic interest, but the reader is overawed by theamount of research going on worldwide and the technology that has been developed.

Chapter 12 discusses the genetics of cattlebehaviour under the headings of social, temperament, sexual, maternal and feeding behaviour.

Chapter 13, on reproduction in cattle, discussesresearch on twinning, age at puberty, gestation lengths, dystocias, conception rate etc., and is very theoretical.

Chapter 14 is very interesting, providing background information on the development of in vitro embryo production, cloning and transgenic livestock production.

Chapter 15 is a very comprehensive chapter on embryo development, thegenesand chromosomesinvolved and the determination and differentiation of the sex. The chapter discusses all thestagesfrom conception to birth and goesinto minute detail.

Chapter 16 is a very philosophical chapter on genetic resources and conservation.

Chapter 17 is about the advantages, pitfalls and possibility of Marker Assisted Selection (MAS). Although the author gives a good explanation of what MAS is, he only speculates about the value of it and does not give any real facts, but it gives you a good idea of what the future in cattle breeding may hold. In Chapter 18, various aspects of genetic improvement of dairy cattle are discussed, giving the background, the basics and also some of the latest developments followed by a chapter on molecular genetics of milk production. Although a basicknowledge of molecular biology and physiology is needed to understand these chapters, they providea valuable reference. Genetic improvement of beef cattle in Chapter 20iswritten for European conditions. It is a pity that the authors did not refer to theSouth African Scheme, which is one of the most comprehensiveand developed schemes in the world.

Chapter 21 on the genetics of meat quality, is a very interesting chapter. There is a worldwide tendency for breed-branded marketing of beef, and this chapter provides a good background on scientific breeding of animals with quality meat.

Thenext chapter, on cattle adaptation in the tropics, is very informative. The authors discuss various interesting topics such as the economic values, breeding objectives and their practical implications.

Chapter 23, genetic nomendature for cattle, unfortunately only refers to discussions at workshops of the committee of Genetic N omenclature for sheep and goats.

All the breeds of cattle are listed in the last chapter, with tables referring to their distribution, colours, characteristics etc. and there is a list of authors and publications on each breed. South African breeds and authors are conspicuous by their absence.

This is a valuable reference book for anybody interested in cattle. It covers a widespectrum in the field of genetics. To be able to understand and use the whole book is impossible for the average reader, but it is a wonderful reference book to have if you are in the field of genetics. Some chapters were written for a very narrow spectrum of scientists and are of very little value for the average veterinarian. Others are of general interest to the novice/farmer/veterinarian. As South Africa has a long history of cattle breeding and its research, and also has one of the best-developed cattle improvement schemes in the world, not to mention our sought-after cattle breeds, it is a great pity that the authors of this book totally ignored us.

$\mathbf{F} \mathbf{J}$ de Villiers

ARC - Animal Improvement Institute Irene 